\section{EFFECT OF AIR FLOW OBSTRUCTION IN A CONDENSING UNIT ON SPLIT AIR CONDITIONER PERFORMANCE}

\author{
Andriyanto Setyawan*
}

Department of Refrigeration and Air Conditioning Engineering, Politeknik Negeri Bandung, Bandung 40012, Indonesia
Article history

Received

2 September 2019

Received in revised form

14 March 2020

Accepted

28 June 2020

Published online

27 August 2020

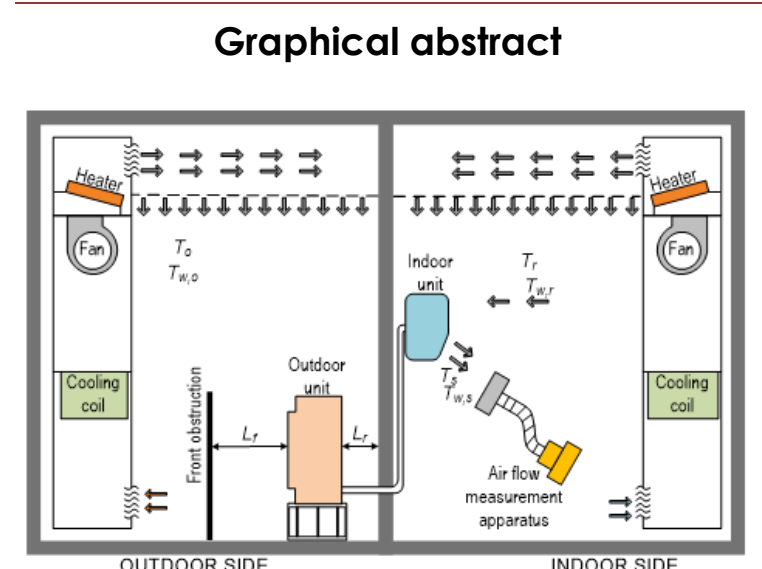

OUTDOOR SIDE

\section{Abstract}

Obstructions of air flow in the outdoor unit could block the condenser air flow and reduce its heat rejection As a result, it could decrease the performance of a room air conditioning system. The paper presents the effects of the air flow obstruction of a condensing unit on the performance of a split-type air conditioner with refrigerant R410A. The study was conducted experimentally by employing front and side obstructions with varied distance from the condensing unit. The front obstruction of $100 \mathrm{~cm}$ height was applied at varied distance from $10 \mathrm{~cm}$ to $100 \mathrm{~cm}$, while the side obstruction of the same height was applied at distance of 5,10 , and $15 \mathrm{~cm}$. The presence of air flow obstructions results in the decrease of cooling capacity and coefficient of performance (COP). On the other hand, it increases the input power of the $A C$ unit. From the experiment, it is obvious that the distance of front obstruction of $10 \mathrm{~cm}$ results in the reduction of cooling capacity by $46 \%$ and COP by $56 \%$. It is also revealed that the distance of the front obstruction of $50 \mathrm{~cm}$ or more has no significant effect for the performance of the air conditioning unit. In addition, the side obstructions have the less significant effect than that of the front obstruction.

Keywords: Air flow obstruction, coefficient of performance, condensing unit, cooling capacity

(C) 2020 Penerbit UTM Press. All rights reserved

\subsection{INTRODUCTION}

Placement and arrangement of outdoor units or condensing units have been recognized as important factors in air conditioning system efficiency. To maintain the good appearance of a building, however, the condensing unit is sometimes installed at improper locations that disturb the air flow in condensing unit and degrade the performance of air conditioning units. In a high-rise building, the condensing units are often installed at the building re-entrant, sucked condenser's cooling air from the re-entrant and discharge it to the open space.

Instead of discharging condenser air to the open space, Chow et al. [1] suggested to suck cooling air from the open space and discharge it into the light well in a high-rise building. In addition, the air leaving from condenser should be maintained to avoid of air flow back into the air conditioning machine room [2]. For installation of condensing units in a light well, Nada and Said [3] reported that the condensing units installed in the lower levels have a poorer performance than those installed in the higher level. However, the performance will not be affected by the height of the installation if mechanical ventilation was used.

Improper installation of condensing unit also leads to the performance degradation of air conditioning system due to increase of coil temperature. Xue et al. [4] reported that the temperature of cooling air could increase more than $20^{\circ} \mathrm{C}$ in a confined space where the condensing units were installed. A 
decrease of COP by $2 \%$ for each increase $1^{\circ} \mathrm{C}$ of outdoor air dry-bulb temperature has been reported by Yau and Pean [5]. For a household refrigerator installed in a room, Bassiouny [6] reported that a space of more than $20 \mathrm{~cm}$ behind the refrigerator would result in temperature decrease of air around the condenser and increase its heat rejection to the surrounding. To study the effects of air blockage in the inlet side of a condensing unit, Datta et al. [7] carried out an experiment by blocking the air flow in condensing unit of an automotive air conditioning system. They testified that the blockage of $50 \%$ of air flow through the condenser decrease the cooling capacity by $8.16 \%$ and COP by $16.8 \%$. The effect of the partially blocked air flow on the effectiveness of a finned-tube heat exchanger has also been studied by Blecich [8]. He informed that the moderate air flow non uniformity caused a decrease of heat exchanger effectiveness by $5 \%$ to $10 \%$. For severe non uniformity, however, the decrease of effectiveness could reach $30 \%$. Avara and Daneshgar [9] conducted simulation to obtain the optimum distance between the condensing unit and the rear wall where the condensing unit was mounted. The simulation was conducted under various distances of the adjacent walls in the rear and front of the condensing unit. They proposed distances of $35 \mathrm{~cm}, 75 \mathrm{~cm}$, and $50 \mathrm{~cm}$ for the distance between walls of $1.5 \mathrm{~m}, 2 \mathrm{~m}$, and $3 \mathrm{~m}$. In powerplant, improper condenser layout could also degrade the performance of an air-cooled condenser [10]. On the other hand, air flow deflector could be used for improving the condenser performance under windy environment $[10,11]$.

In this study, the examination of the mutual effect of the front and side air flow obstruction in a condensing unit has been experimentally carried out. This paper describes the effect of air flow obstruction in the condensing unit on the performance of air conditioning unit. The description comprises of its effects on the discharge and suction pressure, condensing temperature, cooling capacity, input power, and coefficient of performance (COP).

\subsection{METHODOLOGY}

The experiment was conducted by using an R410A split-type air conditioner with a nominal cooling capacity of $2.64 \mathrm{~kW}$ and input power of 800 Watts. The experiment was carried out in a conditioned psychrometric chamber (Figure 1). The chamber consists of two rooms representing the indoor and outdoor conditions. The outdoor unit of the air conditioner was installed at a distance of $20 \mathrm{~cm}$ from the wall in outdoor side of the chamber. During the experiment, the outdoor air chamber DB and WB temperatures were controlled at $35^{\circ} \mathrm{C}$ and $24^{\circ} \mathrm{C}$, respectively. Meanwhile, the indoor $\mathrm{DB}$ and WB temperatures were controlled at $27^{\circ} \mathrm{C}$ and $19^{\circ} \mathrm{C}$, respectively. These conditions are in accordance with ISO Standard 5151:2017. The control of outdoor and indoor chambers' conditions was carried out by using cooling coils, electric heaters, and fans. The equipment were installed in each chamber.

To observe the effect of the front and side obstruction on the performance of air conditioning system, an experimental setup as shown in Figure 2 was constructed. The outdoor unit of the air conditioning system was surrounded by "walls"; in which one was located at the front at a distance of $L_{f}$ and two were located at the side of the outdoor unit with equal distance of Ls for the right and left side. A constant distance from the rear wall of $L_{r}(20$ $\mathrm{cm}$ ) was maintained at the rear of the outdoor unit. The height of the obstruction is $1 \mathrm{~m}$, considering the common height of balcony shield in common apartment buildings. Under this condition, a part of the discharged air from the condenser is blocked by the obstruction and the remaining could flow above the obstruction and discharged to the open space.

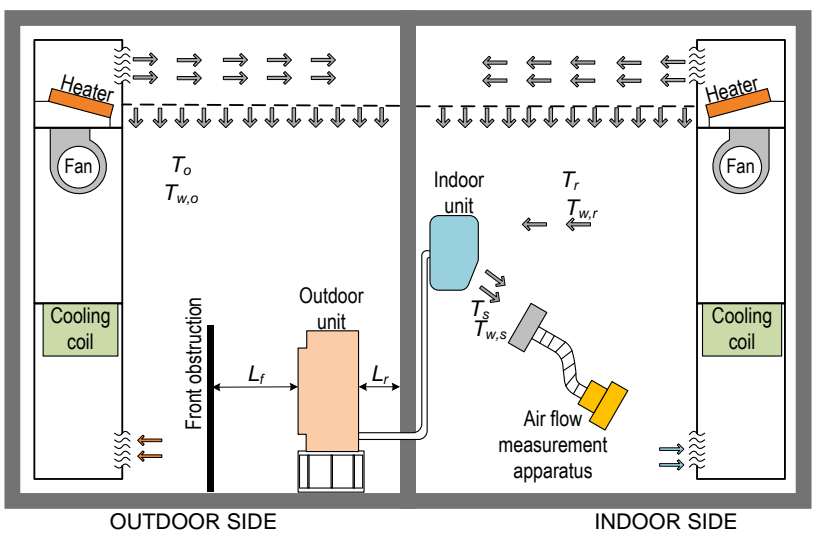

Figure 1 Experimental setup in psychrometric chamber

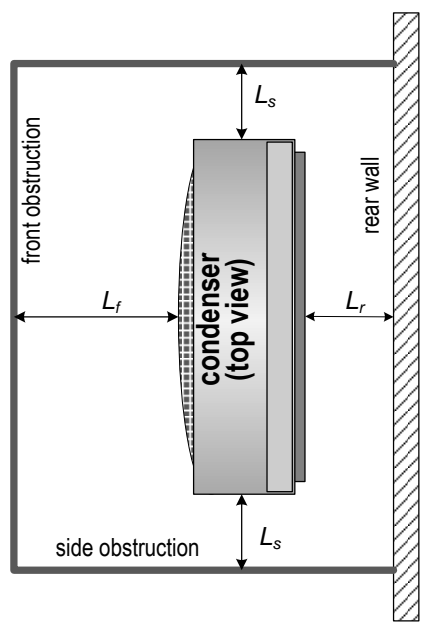

Figure 2 Detail of the condenser air flow obstruction experiment (top view). The condensing unit is at a distance of $L_{r}, L_{s}$, and $L_{f}$ from rear, side, and front obstructions

In this experiment, the side obstruction distance was varied at 5,10 , and $15 \mathrm{~cm}$, while the front 
obstruction distance was varied at 10, 15, 20, 25, 30, $35,40,50$, and $100 \mathrm{~cm}$. The variation of the distance of the side and front obstructions is aimed to examine the effects of the distance of the obstructions on the performance of the air conditioner.

The experimental matrix is presented in Table 1. The numbers $1,2, \ldots, 27$ describe the number of runs of the experiment. For instance, Run \# 1 was carried out under front distance of $10 \mathrm{~cm}$ and side distance of $5 \mathrm{~cm}$ and Run \#14 was carried out at front distance of $30 \mathrm{~cm}$ and side distance of $10 \mathrm{~cm}$. During the test, the distances of the obstructions were changed manually, following the experimental matrix.

Table 1 Experimental matrix

\begin{tabular}{ccccccccccc}
\hline $\begin{array}{c}\text { Side distance } \\
(\mathbf{c m})\end{array}$ & $\mathbf{1 0}$ & $\mathbf{1 5}$ & $\mathbf{2 0}$ & $\mathbf{2 5}$ & $\mathbf{3 0}$ & $\mathbf{3 5}$ & $\mathbf{4 0}$ & $\mathbf{5 0}$ & $\mathbf{1 0 0}$ \\
\cline { 2 - 9 } & 1 & 2 & 3 & 4 & 5 & 6 & 7 & 8 & 9 \\
$\mathbf{5}$ & 10 & 11 & 12 & 13 & 14 & 15 & 16 & 17 & 18 \\
10 & 19 & 20 & 21 & 22 & 23 & 24 & 25 & 26 & 27 \\
\hline
\end{tabular}

To examine the performance of the air conditioning system, the following parameters were measured: discharge pressure and temperature, suction pressure and temperature, refrigerant temperature entering and leaving the condenser, and refrigerant temperature entering and leaving the evaporator. The air-side capacity of the air conditioning machine was examined based on the measurement of the dry-blub (DB) and wet-bulb (WB) temperatures of air entering and leaving the evaporator. In addition, the DB and WB temperatures of air entering and leaving the condenser were also measured to examine its effect on the condenser performance in rejecting heat from the refrigerant to the surrounding. This configuration is different from that of Datta et al. [7], in which the obstructions were placed at the upstream of condenser.

Examination of the refrigerant-side performance was carried out by measuring the suction and discharge pressures (P1 and P2) and temperatures (T1 and T2), liquid line temperature (T3), and temperature of refrigerant entering the evaporator (T4). The diagram of the refrigeration system for this experiment is depicted in Figure 3. The measurements of $\mathrm{P} 1, \mathrm{P} 2, \mathrm{~T} 1, \mathrm{~T} 2$, and $\mathrm{T} 4$ are used for determining the enthalpy of refrigerant entering the evaporator, leaving the evaporator, and leaving the compressor. T3 is used for determining the condensing temperature of refrigerant. These data are then utilized for determining the performance of the air conditioner.

The measurement of discharge and suction pressures were performed by using Bourdon type pressure gauges with accuracy of $\pm 1.6 \%$. For temperature measurements, temperature data loggers with accuracy of $\pm 0.2 \%$ reading and $\pm 0.5^{\circ} \mathrm{C}$ were used. The measurement of wet-bulb temperature was performed by covering the sensor with wick wetted by distilled water. Measurement of air flow rate was performed by using hood air flow meter with an accuracy of $\pm 3.0 \%$ of reading. The voltage, current, and power consumption of the air conditioning unit were measured by a digital power meter with an accuracy of $0.1 \%$ of reading $\pm 0.05 \%$ of measurement range.

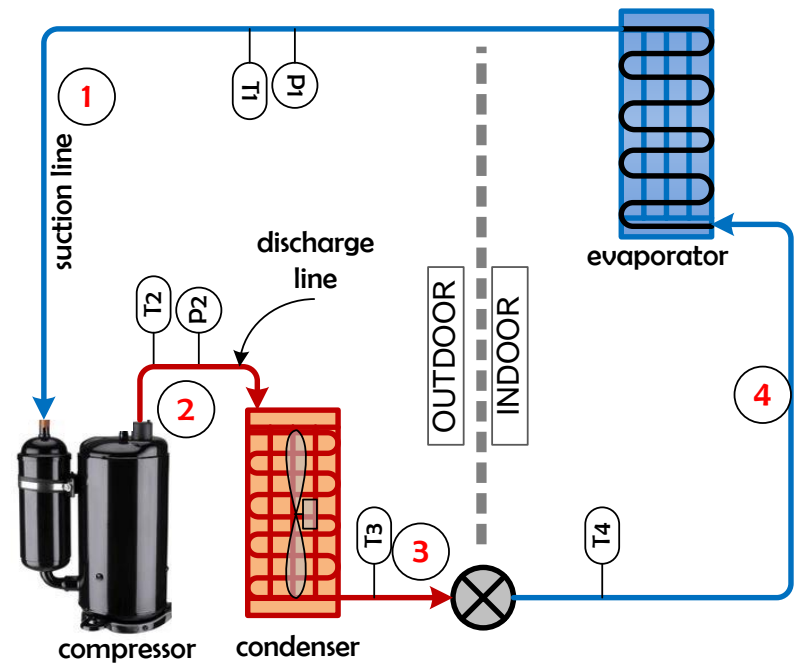

Figure 3 Refrigeration cycle of room air conditioner and its measuring points (refrigerant-side)

The cooling capacity of the air conditioner can be calculated by

$$
q_{E}=\dot{m} \Delta h
$$

Where $q_{E}$ is the cooling capacity (W), $\dot{m}$ is air mass flow rate through the evaporator, and $\Delta h$ is the enthalpy difference of air entering and leaving the evaporator. The enthalpy difference of air can be expressed as

$$
\Delta h=h_{r}-h_{s}
$$

in which $h_{r}$ is and $h_{s}$ represent the return and supply air enthalpy, respectively. The air mass flow rate can be calculated by

$$
\dot{m}=\rho Q
$$

where $\rho$ is the air density and $Q$ is the volumetric flow rate of air across the evaporator. The mass flow rate can also be calculated by

$$
\dot{m}=\frac{Q}{v}
$$

where $v$ is the specific volume of the air that can be read from psychrometric chart. 
The performance of the air conditioner in the refrigerant side could be expressed as its COP (coefficient of performance) and EER (energy efficiency ratio). The COP could be determined by

$$
\mathrm{COP}=\frac{h_{1}-h_{4}}{h_{2}-h_{1}}
$$

In this equation, $h$ represents the refrigerant enthalpy and subscripts 1, 2, 4 denote the suction, discharge, and entering evaporator in the refrigeration cycle. The EER of the air conditioner could be expressed as

$$
E E R=\frac{q_{E}}{P} .
$$

where $P$ is the electrical power drawn by the air conditioner and can be obtained from measurement. In the calculation of EER, all power required to operate the compressor, fans, and control device are taken into account.

During the test, the DB and WB temperature of the outdoor chamber could be controlled at the range of $35^{\circ} \mathrm{C}$ and $24^{\circ} \mathrm{C}$, respectively. In the indoor side, the $\mathrm{DB}$ and $\mathrm{WB}$ temperature could be maintained at $27^{\circ} \mathrm{C}$ and $19^{\circ} \mathrm{C}$, correspondingly.

\subsection{RESULTS AND DISCUSSION}

During the experiment, the temperature of the outdoor chamber was recorded at $35 \pm 0.04^{\circ} \mathrm{C} \mathrm{DB}$ and $23.9 \pm 0.03^{\circ} \mathrm{C} \mathrm{WB}$. Meanwhile, the indoor chamber temperature was recorded at $27 \pm 0.05^{\circ} \mathrm{C} D B$ and $19 \pm 0.03^{\circ} \mathrm{C} W B$.

\subsection{Discharge and Suction Pressure}

Under normal installation with no front and side obstructions, the discharge pressure of refrigerant was measured to be $24.8 \pm 0.17$ bar absolute. Due to the obstructed air flow in the front and side of the condensing unit, the air flow across the condenser coil was disturbed. It results in the decrease of heat transfer in the condenser due to the reduction of air flow across the condenser, causing the increase of discharge pressure. When the side obstruction was set at $5 \mathrm{~cm}$, the discharge pressure varied from 28.6 bar to 24.8 bar gauge for the front obstruction distance of 10 to $100 \mathrm{~cm}$. At the side obstruction distance of $10 \mathrm{~cm}$, the discharge pressure varied from 28 bar to 24.8 bar for the same distance range of front obstruction. Finally, at the side obstruction distance of $15 \mathrm{~cm}$, the discharge pressure slightly decreases in the range of 27.7 bar to 28.0 bar gauge. The pressure data have uncertainties of \pm 0.11 bar for discharge pressure and \pm 0.17 bar for suction pressure. This phenomenon is similar to that of Datta et al. [7], in which the blockage of the air flow through the condenser increases the discharge pressure. For the suction side, the pressure increases as the distance of the front obstruction decreases. The effect of the front and side obstruction on the discharge and suction pressure is provided in Figure 4.
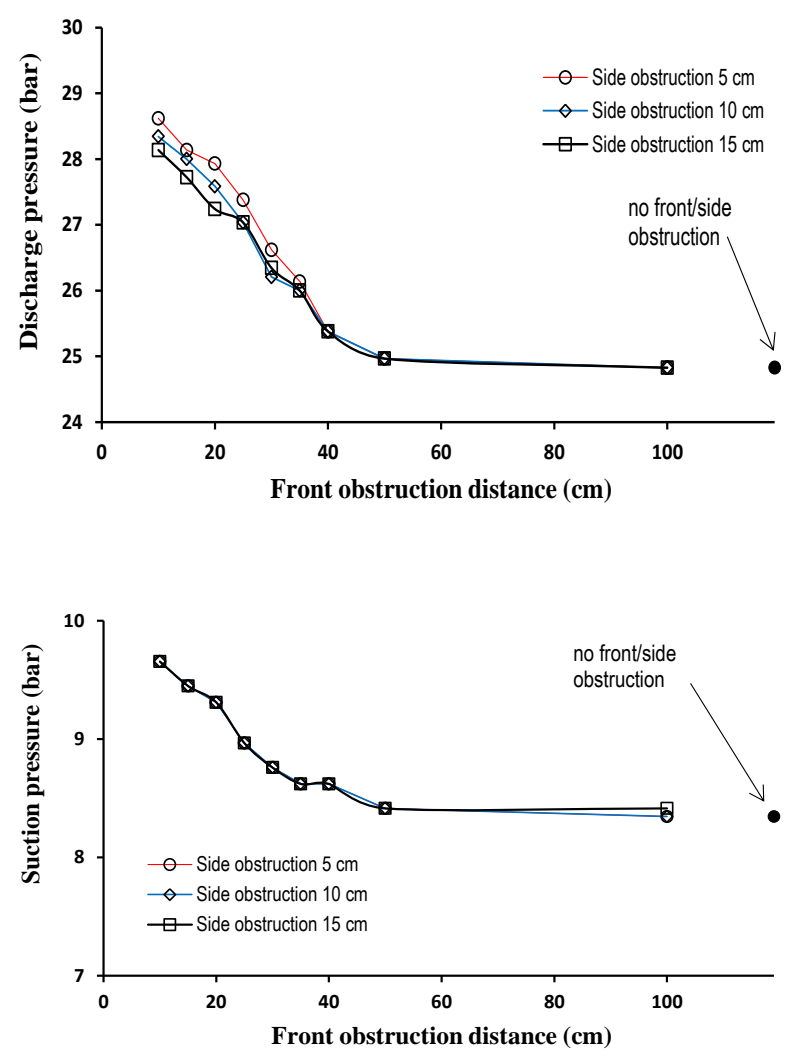

Figure 4 Effect of front and side obstructions on the discharge pressure (top) and suction pressure (bottom)

\subsection{Supply Air Temperature}

The installation of front and side obstructions also influences the supply air temperature from the evaporator. Under normal condition without any obstruction, the supply air temperature is about $16.3^{\circ} \mathrm{C}$. Here, the term supply air is used for the air leaving the evaporator and supplied to the room. The blockage of discharge air from condenser by a distance of $10 \mathrm{~cm}$ from the condenser outlet results in the supply air temperature of $19.7^{\circ} \mathrm{C}$, or increase by $3.4^{\circ} \mathrm{C}$. This implies the degradation of the performance of the air conditioning in lowering the air temperature passes the evaporator. As the front obstruction distance increases, the supply air temperature decreases, indicates the better performance. As presented in Figure 5, the effect of the side obstruction on the system performance is less significant than that of the front obstruction. Detailed examination also reveals that at the distance of 50 $\mathrm{cm}$ or more, the effect of the front obstruction is no longer significant. 


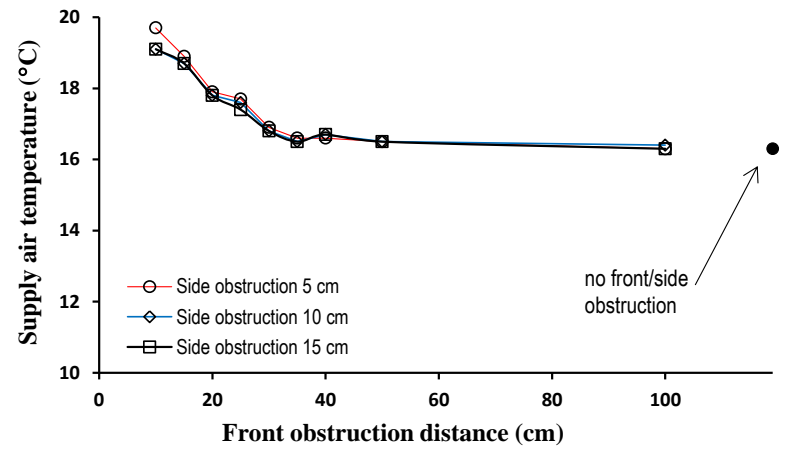

Figure 5 Effect of front and side obstructions on the air temperature at evaporator outlet

\subsection{Condenser Outlet Air Temperature}

The existence of the flow barriers at the front and sides of the condenser also affect the condenser outlet air temperature. In Figure 6, it is shown that the air temperature after passing the condenser coil has a higher temperature if the front and side distances of the flow barrier decrease. It could be caused by the decreases of the net air flow when the distances of the barriers decrease. Other possible cause is the short-circuited air flow discharged by the condenser when the barriers' distances are small. A certain part of the air at the condenser outlet could flow back and sucked by the condenser fan. This sort of air is the mixed with the fresh air and, therefore, increases the inlet air temperature to the condenser.

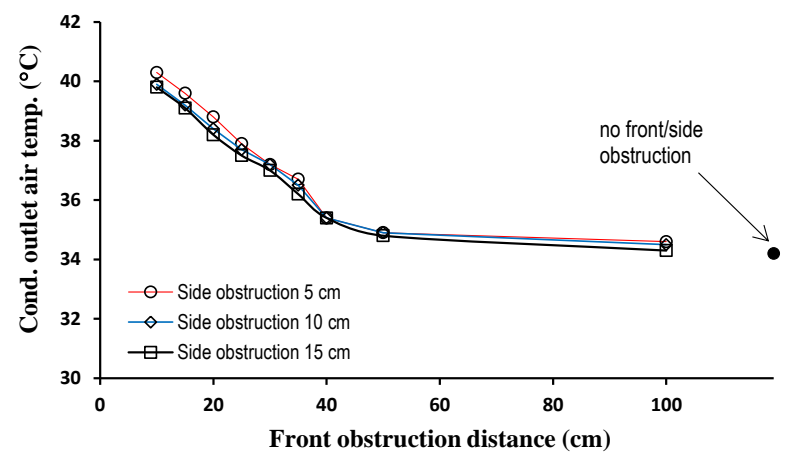

Figure 6 Effect of front and side obstructions on the air temperature at condenser outlet

At the front barrier distance of $50 \mathrm{~cm}$ and more, the air temperature at the condenser outlet only slightly decreases. This is contrast to the condition of the condenser outlet air temperature for the shorter distances from $10 \mathrm{~cm}$ to $50 \mathrm{~cm}$. At the distance of front barrier of 50 to $100 \mathrm{~cm}$, the air temperature only has a slight difference to that of the condition without front and side obstruction. It implies that the effect of the front obstruction is no longer significant for the distance of $50 \mathrm{~cm}$ or more. It should be noted that the height of the obstruction is $100 \mathrm{~cm}$ and possibly a large part of the discharged air could flow above the obstruction.

\subsection{Condensing Temperature}

The term condensing temperature is referred to the liquid refrigerant temperature measured at the condenser outlet of the refrigeration circuit. The air flow disturbance across the condenser of air conditioning unit also affects the heat rejection of the condenser. The presence of obstruction disturbed the air flow across condenser, reducing the air flow, and, finally, reducing the heat rejection. Consequently, the temperature of refrigerant at the condenser outlet increases as the distance of the barrier decreases. As could be seen in Figure 5, the refrigerant temperature at the condenser outlet could reach $46 \cdot 3^{\circ} \mathrm{C}$. Meanwhile, at the normal condition without any obstruction, the refrigerant temperature at this position is averagely $36^{\circ} \mathrm{C}$. As the distance between the obstruction and the condenser increases, the refrigerant temperature at the condenser outlet decreases. Detailed examination of Figure 7 reveals that at the barrier distance of $50 \mathrm{~cm}$ or more, the effect of the flow obstruction is no longer significant. For a comparison, Duan et al. [12] reported a decrease of operating temperature of outdoor unit from $46.5^{\circ} \mathrm{C}$ to $42^{\circ} \mathrm{C}$ for the variation of distance between condensing units of $0.3 \mathrm{~m}$ to $0.7 \mathrm{~m}$.

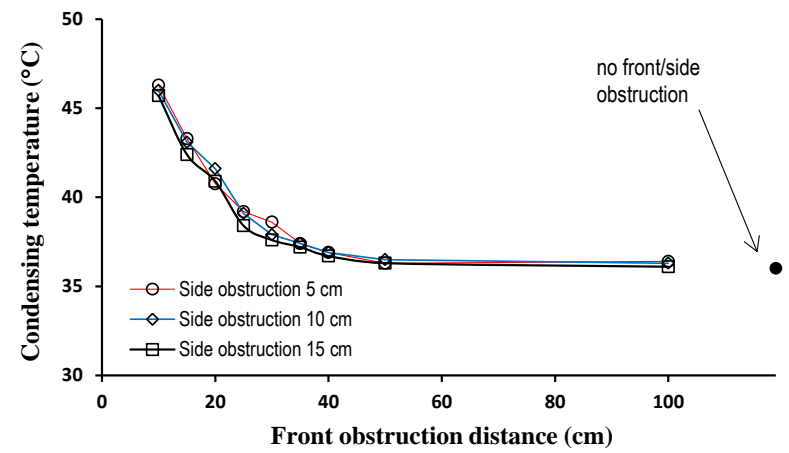

Figure 7 Effect of front and side obstructions on the condensing temperature

\subsection{Input Power}

Due to the high condensing temperature under the presence of the obstructions, the power consumed by the air conditioning machine increases as distance of obstruction decreases. In Figure $8 \mathrm{a}$, it is shown that the input power curve has a similar trend to that of condensing temperature. At a distance of $50 \mathrm{~cm}$ or more, the obstruction has no more significant effect on the power consumption. At the absence of obstruction, the average power consumption is about 770 Watt. This includes the power drawn by the compressor, condenser fan, and evaporator fan. At the distance of front obstruction 
of $50 \mathrm{~cm}$ and $40 \mathrm{~cm}$, the power consumption is the same 770 Watt for side obstruction distance of $15 \mathrm{~cm}$. For side distance of $5 \mathrm{~cm}$, the power consumption is found at 792 Watt. As the front obstruction distance reduced to $30 \mathrm{~cm}$, the power consumption is in the range of 814 to 836 Watt. For the closest distance of front obstruction $(10 \mathrm{~cm})$, the power consumption increases to the range of 968 to 1012 Watt. In general, each $1^{\circ} \mathrm{C}$ of increase of condensing temperature, the input power increase by averagely $2.4 \%$ (Figure 8b). Meanwhile, Kumbhar et al. [13] reported an increase of input power by $1.7 \%$ for each $1^{\circ} \mathrm{C}$ increase of condensing temperature.

\subsection{Cooling Capacity}

The effect of condenser air flow obstructions on the cooling capacity is resumed in Figure 9. To calculate the cooling capacity, equations 1 to 4 are used. Under the closest front obstruction distance $(10 \mathrm{~cm})$, the cooling capacity is in the range of 1187 to 1197 Watts. Meanwhile, at the normal condition, the capacity is about 2205 Watts. The cooling capacity drops to $54 \%$ from its normal capacity when the condenser air flow is blocked at a distance of $10 \mathrm{~cm}$. Observation of Figure $9 a$ reveals that the effect of the front obstruction is more significant than that of the sides. In addition, the effect of the front obstruction is no longer significant when the front obstruction is located at a distance of $100 \mathrm{~cm}$ or more.

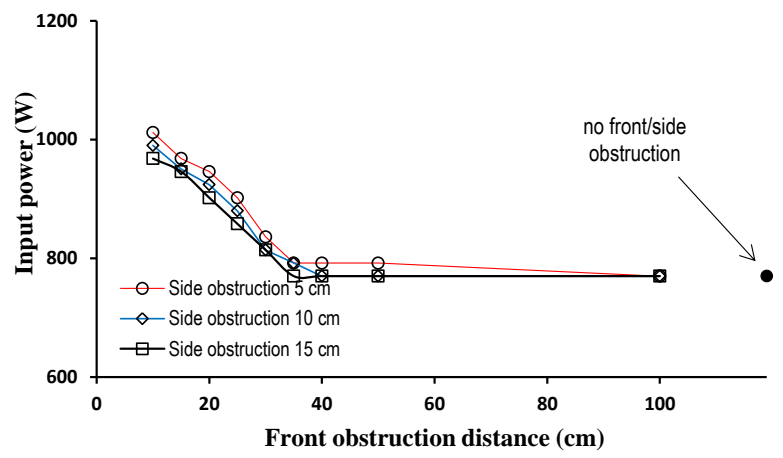

a.

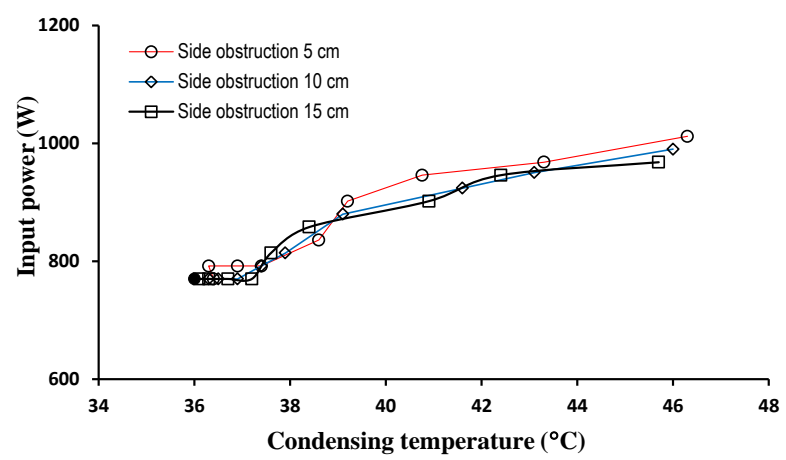

b.

Figure 8 Input power as function of side obstruction and a. front obstruction, and b. condensing temperature
The plot of cooling capacity as a function of condensing temperature is provided in Figure 9b. As seen in this figure, the cooling capacity decrease by about $46 \%$ when the condensing temperature increases from $36^{\circ} \mathrm{C}$ to $46.3^{\circ} \mathrm{C}$. As a comparison, the cooling capacity could decrease by $32 \%$ for an increase of condensing temperature from $42^{\circ} \mathrm{C}$ to $49.5^{\circ} \mathrm{C}$ [14]. Meanwhile, Datta et al. [7] reported the reduction of cooling capacity with the percentage of the blockage of air flow across the condenser. In addition, the increase of the distance of condensing unit and wall from $8 \mathrm{~cm}$ to $30 \mathrm{~cm}$ could improve the cooling capacity by $30.4 \%$ [15].

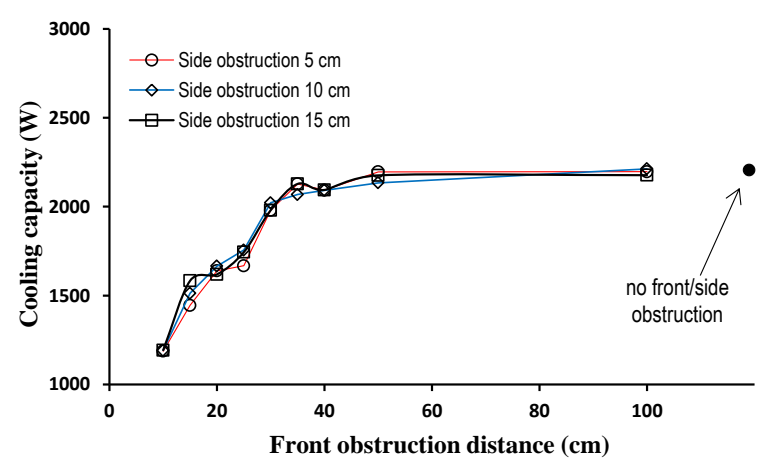

a.

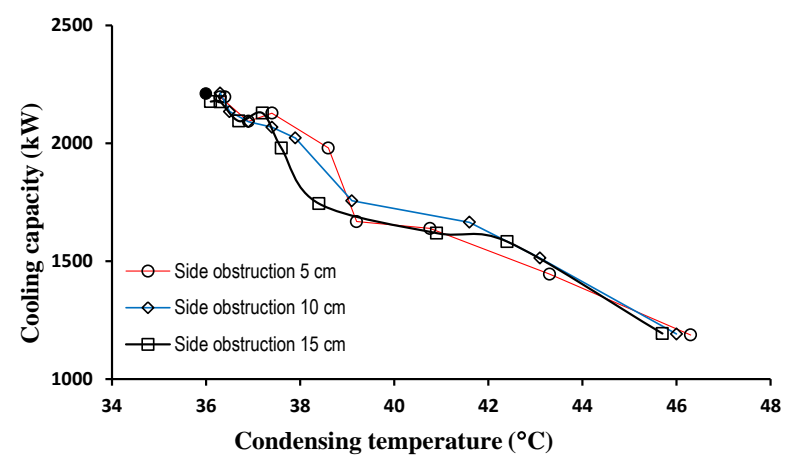

b.

Figure 9 Cooling capacity as function of a. obstruction distance, b. condensing temperature

\subsection{COP}

As the cooling capacity and the power consumption have been examined, the COP or EER of the air conditioning machine now can be determined. In this paper, the COP is defined as the cooling capacity resulted by the machine and the total input power consumed by the machine, i.e. the compressor, condenser fan, and evaporator fan. In normal condition without any obstruction, the COP was calculated to be 2.87. From Figure 10a, it can be observed that the use of flow obstruction, especially in the front position, can reduce the COP significantly. At the distance of front obstruction of 10 $\mathrm{cm}$, the COP drops to averagely 1.2. The COP increases as the distance of the front obstruction increases. At the distance of the obstruction reaches 
$100 \mathrm{~cm}$, the COP reaches 2.85. For the front obstruction distance of $100 \mathrm{~cm}$ or more, the obstruction has no significant effect on the COP.

The plot of COP as a function of condensing temperature is presented in Figure 10b. As could be seen, the higher condensing temperature results in the lower COP. The COP varied from 2.87 to 1.2 for the condensing temperature variation from $36^{\circ} \mathrm{C}$ to $46.3^{\circ} \mathrm{C}$. As a comparison, Elsayed and Hariri [14] reported a reduction of COP by $45 \%$ for the variation of condensing temperature from $42^{\circ} \mathrm{C}$ to $49.5^{\circ} \mathrm{C}$. Report from Jin et al. [15] showed an insignificant change in COP in their experiment using a front louver if the distance was increased from $30 \mathrm{~cm}$ to 50 $\mathrm{cm}$. Numerical analysis of top discharged condensing unit showed the similar result, in which the COP only slightly affected by the front wall distance if the wind was directed from the rear of the condensing unit [16]. Meanwhile, the temperature of outdoor unit increases as the outdoor wind speed increases [17].

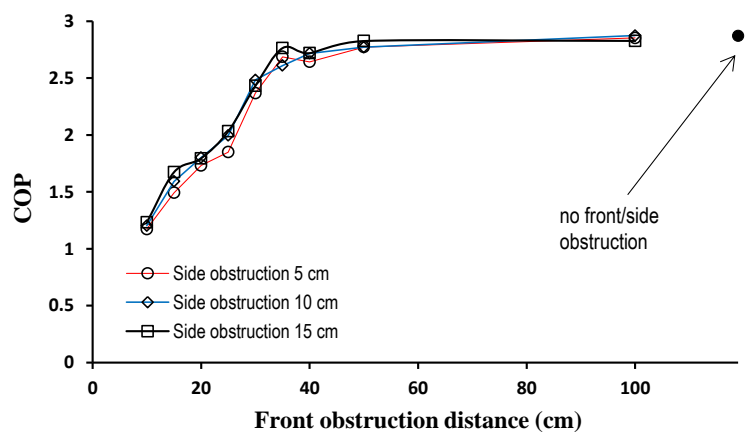

a.

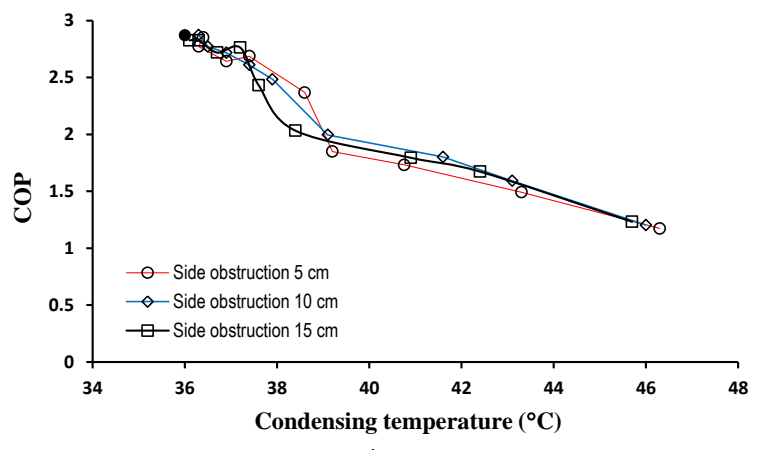

b.

Figure $10 \mathrm{COP}$ as function of a. obstruction distance, b. condensing temperature

\subsection{CONCLUSION}

The performance of air conditioning under front and side air flow obstruction in the condensing unit has been experimentally investigated. The analysis on the discharge and suction pressure, condensing temperature, cooling capacity, input power, and COP have also been carried out. Generally, the increase in front obstruction distance results in the decrease of discharge and suction pressure, decrease of condensing temperature, increase of cooling capacity, decrease of input power, and increase of system COP. At the distance of $50 \mathrm{~cm}$ or more, the front obstruction has no longer significant effect on the suction and discharge pressure, condensing temperature, input power, cooling capacity, and COP. At the closest distance of the front obstruction $(10 \mathrm{~cm})$, the cooling capacity decreases by $46 \%$ as compared to the normal condition without any obstruction. For the same experimental condition, the input power increases by $29 \%$ to $31 \%$ and the COP decreases by $56 \%$. The experiment also showed that the variation of side obstruction distance has a less significant effect than that of front obstruction distance.

\section{Acknowledgement}

The author would like to thank to the Department of Refrigeration and Air Conditioning Engineering, Politeknik Negeri Bandung, for the support during the accomplishment of this research

\section{References}

[1] Chow, T. T., Lin, Z., and Wang, Q. W. 2001. Flow Analysis of Condenser Cooling Air Delivery via Building Light Well. Applied Thermal Engineering. 21: 831-843. https://doi.org/10.1016/S1359-4311 (00)00084-3.

[2] Chow, T. T., Lin, Z., and Yang, X. Y. 2002. Placement of Condensing Units of Split-type Air-conditioners at Low-rise Residences. Applied Thermal Engineering. 22: 1431-1444. https://doi.org/10.1016/S1359-4311 (02)00068-6.

[3] Nada, S. A. and Said, M. A. 2018. Solutions of Thermal Performance Problems of Installing AC Outdoor Units in Buildings Light Wells Using Mechanical Ventilations. Applied Thermal Engineering. 131: 295-310. https://doi.org/10.1016/j.applthermaleng.2017.12.016.

[4] Xue, H., Xu, B., Wu, J., and Wei, Y. 2007. Prediction of Temperature Rise Near Condensing Units in the Confined Space of a High-rise Building. Building and Environment. 42: 2480-2487.

https://doi.org/10.1016/j.buildenv.2006.06.011

[5] Yau, Y. H. and Pean H. L. 2014. The Performance Study of a Split Type Air Conditioning System in the Tropics, as Affected by Weather. Energy and Buildings. 72: 1-7. https://doi.org/10.1016/j.enbuild.2013.12.010.

[6] Bassiouny R. 2009. Evaluating the Effect of the Space Surrounding the Condenser of a Household Refrigerator. International Journal of Refrigeration. 32: 1645-1656. https://doi.org/10.1016/j.jirefrig.2009.03.011.

[7] Datta, S. P., Das, P. K., and Mukhopadhyay, S., 2014. Obstructed Airflow through the Condenser of an Automotive Air Conditioner - Effects on the Condenser and the Overall Performance of the System. Applied Thermal Engineering. 70: 925-934. https://doi.org/10.1016/j.applthermaleng.2014.05.066.

[8] Blecich, P. 2015. Experimental Investigation of the Effects of Airflow Nonuniformity on Performance of a Fin-andTube Heat Exchanger. International Journal of Refrigeration. 59: 65-74.

https://doi.org/10.1016/j.jirefrig.2015.06.029.

[9] Avara, A. and Daneshgar, E. 2008. Optimum Placement of Condensing Units of Split-type Air-conditioners by Numerical Simulation. Energy and Buildings. 40: 1268-1272. https://doi.org/10.1016/j.enbuild.2007.11.011. 
[10] Huang, X., Chen, L., Kong, Y., Yang, L., and Du, X. 2018. Effects of Geometric Structures of Air Deflectors on Thermo-flow Performances of Air-cooled Condenser. International Journal of Heat and Mass Transfer. 118: 10221039

https://doi.org/10.1016/j.ijheatmasstransfer.2017.11.071.

[11] Huang, X., Chen, L., Yang, L., Du, X., and Yang, Y. 2019. Cooling Performance Enhancement of Air-cooled Condensers by Guiding Air Flow. Energies. 12:1-28. https://doi.org/10.3390/en12183503.

[12] Duan, R., Wang, X., Song, Y., and Liu, J. 2016. Influence of Air-conditioning Outdoor Unit Arrangement Strategy on Energy Consumption. Procedia Engineering. 146: 350-358. https://doi.org/10.1016/j.proeng.2016.06.409.

[13] Kumbhar, A., Gulhane, N., and Pandure, S. 2017. Effect of Various Parameters on Working Condition of Chiller. Energy Procedia. 109: 479-486.

https://doi.org/10.1016/j.egypro.2017.03.076.
[14] Elsayed, A. O. and Hariri, A. S. 2011. Effect of Condenser Air Flow on the aPerformance of Split Air Conditioner. World Renewable Energy Congress, 8-13 May 2011. Sweden. 2134-2141.

[15] Jin, W., Zheng, Y., Zhang, Y., Jiang, Y. 2015. Experimental Study of Factors Affecting the Performance of a Semi Enclosed Outdoor Air-conditioning Unit. Procedia Engineering. 121: 1713-1720. https://doi.org/10.1016/j.proeng.2015.09.138.

[16] Ryu, K., Lee, K. S., and Kim, B. S. 2013. Optimum Placement of Top Discharge Outdoor Unit Installed Near a Wall. Energy and Buildings. 59: 228-235. https://doi.org/10.1016/j.enbuild.2012.12.019.

[17] Choi, S. H., Lee, K. S., and Kim, B. S. 2005. Effects of Stacked Condensers in a High-rise Apartment Building. Energy. 30: 968-981. https://doi.org/10.1016/j.energy.2004.08.004. 